\title{
Giorgio Agamben y la democracia. Hacia una política de lo ingobernable
}

\author{
Giorgio Agamben and democracy. \\ Towards a politics of ungovernable
}

\author{
Manuel Ignacio Moyano ${ }^{1}$ \\ Universidad Nacional de Córdoba (Argentina)
}

Recibido: 06-05-14

Aprobado: 30-07-14

\section{Resumen}

En este trabajo nos proponemos desarrollar los análisis sobre la gloria, la soberanía y el gobierno del filósofo italiano Giorgio Agamben, para intentar dar cuenta de un nuevo uso de la noción "democracia" que escape a estos paradigmas de poder. En este sentido, buscamos plantear desde el pensamiento del autor una democracia que ya no se piense desde una ficticia soberanía popular como tampoco desde una tecnificación administrativa, ni mucho menos desde la casi mística articulación entre ambas, sino precisamente a partir de su desarticulación. Quisiéramos darle a este gesto político el nombre de ingobernable democrático.

Palabras-clave: democracia, soberanía, gobierno, inoperosidad, potencia

\begin{abstract}
In this paper we propose to develop the analysis on glory, sovereignty and government of the Italian philosopher Giorgio Agamben, to try to elucidate a new use of the notion "democracy" out of these paradigms of power. In this sense, we

\footnotetext{
${ }^{1}$ (manumoyano@gmail.com). Licenciado en Ciencia Política por la Universidad Católica de Córdoba, Argentina. Actualmente realiza su doctorado en Filosofía por la Universidad Nacional de Córdoba, sobre la obra del filósofo italiano Giorgio Agamben. Entre sus publicaciones están: “Ontología de la inoperancia. La política en el pensamiento de Giorgio Agamben”, en Biset, E. y Farrán, R. edits, Ontologías políticas, Editorial Imago Mundi, 2011, Buenos Aires, 256 p., pp. 123-150; La puta y la política, en "Revista Studia Politicae", 16 primavera-verano 2008-2009, EDUCC, pp. 59-74; Fuera del ser. Comunidad, humanidad y animalidad en el pensamiento de Giorgio Agamben, en "Revista electrónica de Filosofía Paralaje”, 9, 2013, http://paralaje.cl/index.php/paralaje/article/view/240
} 
try to suggest from the author's thought a democracy that is no longer considered as a fictional popular sovereignty or as an administrative technique, neither as the almost mystical articulation between them, but precisely from their dislocation. We wish to name this political gesture ungovernable democratic.

Key-words: democracy, sovereignty, government, inoperativity, potency.

\section{Introducción}

En un brevísimo texto de reciente publicación llamado "Nota preliminar sobre el concepto de democracia", Giorgio Agamben nos recuerda que hoy en día dicho concepto se mueve en un tensión polar que define dos formas del hacer político: como forma de constitución del cuerpo político y como técnica de gobierno. Ahora bien, es precisamente el punto de articulación y/o desarticulación entre ambos modelos lo que define para el autor la democracia en Occidente. En palabras del mismo,

\footnotetext{
El sistema político occidental es fruto de la fusión de dos elementos heterogéneos, que mutuamente se legitiman y se dan consistencia: una racionalidad político-jurídica y una racionalidad económico-gubernamental, una «forma de constitución» y una «forma de gobierno» ${ }^{2}$.
}

Siguiendo las últimas obras publicadas en continuidad de su trabajo capital Homo sacer. El poder soberano y la nuda vida, y principalmente teniendo en cuenta las reflexiones de El reino y la gloria. Una genealogía teológica de la economía y del gobierno, esta "anfibología" presente en toda discusión sobre la democracia es, para Agamben, fruto de un entrecruzamiento entre dos paradigmas provenientes de la teología cristina: el teológico político y el teológico económico. Mientras el primero plantearía la trascendencia soberana de todo poder, el segundo postularía la ordenación inmanente y doméstica - esto es, técnica- de la vida. De acuerdo al italiano, el engranaje de ambos paradigmas estará situado en las funciones doxológicas y aclamativas de las ceremonias y los protocolos que en la vida política de las actuales democracias se mantienen en plena concordancia a sus desarrollos teológicos. A este lugar insustancial y punto de articulación, por medio de una inmensa genealogía, Agamben lo denomina gloria.

En este trabajo nos proponemos retomar estos análisis sobre la gloria, la soberanía y el gobierno, para intentar dar cuenta de un nuevo uso de la noción "democracia" que escape a estos paradigmas. En este sentido, buscamos

\footnotetext{
${ }^{2}$ Giorgio Agamben, Nota preliminar sobre el concepto de la democracia, [en AAVV. Democracia, ¿en qué Estado?, Buenos Aires, Prometeo, 2011], pág. 13.
} 
plantear desde Agamben una democracia que ya no se piense desde una ficticia soberanía popular como tampoco desde una tecnificación administrativa, ni mucho menos desde la casi mística articulación entre ambas, sino precisamente a partir de su desarticulación y punto de fuga. Quisiéramos darle a este gesto político el nombre de ingobernable democrático.

\section{La configuración técnica de la vida humana: gubernamentalidad y gloria}

Contrariamente a las típicas presentaciones del pensamiento agambeniano respecto de sus consideraciones políticas que exponen primero los análisis en torno a la soberanía (desarrollados en Homo sacer I como también en Estado de excepción. Homo sacer II y Lo que queda de Auschwitz. Homo sacer III) y luego muestran cómo dichos análisis sufren una reconsideración por el autor dado que se inclina a analizar las figuras del gobierno y la economía, aquí buscaremos sostener en su bi-polaridad los planos de la exposición para mostrar cómo ambos análisis, el de la soberanía y el del gobierno, se compenetran recíprocamente y dan lugar a un resto excesivo que será precisamente el espacio donde asentar algo así como un ingobernable. En este sentido, y desde una interpretación propia, consideramos que El reino y la gloria. Una genealogía teológica de la economía y del gobierno. Homo sacer II, 2 retoma las consideraciones iniciales sobre la soberanía, la excepción y la nuda vida, para inscribirlas en un nuevo conjunto paradigmático como será la teología económica trinitaria. Por lo tanto, no hay un desecho o total desconexión de las tesis anteriores con las nuevas sobre el gobierno y la economía, sino más bien una re-exposición. Por esto mismo, y por razones de espacio, nos atendremos a un despliegue de lo trabajado en esta última gran publicación para dar cuenta de nuestra visión agambeniana de la democracia.

Así, de una forma torpe y esquemática, podríamos empezar por afirmar que en Agamben el problema de la economía es el problema de la "gestión técnica sobre la vida". De este modo, el esfuerzo que concentra las directrices de $E l$ reino y la gloria consistirá en relacionar el paradigma económico-gestional (que rige actualmente en nuestras sociedades) con el ya estudiado paradigma político-estatal (que se cristaliza en la soberanía schmittiana). En este sentido, la pregunta fundamental que rige las indagaciones del autor versa sobre el punto de confluencia entre el Estado y la economía, y esa amalgama llevará por nombre "la máquina gubernamental". Máquina, en el pensamiento agambeniano, refiere a un dispositivo que pone en relación dos polos heterogéneos que se presentan de forma antinómica, los cuales no preexisten a la misma sino que se producen

\footnotetext{
${ }^{3}$ Rodrigo Karmy Bolton, Introducción, [en Rodrigo Karmy Bolton, ed.: Políticas de la interrupción. Ensayos sobre Giorgio Agamben, Santiago de Chile, Escaparate, 2011], pág. 14.
} 
en esa puesta en relación. Ello es posible porque en el centro de la máquina hay un vacío que permite dicha conexión performativa entre ambos polos, lo que la vuelve puramente funcional e insustancial. Por lo tanto, de esta caracterización de la máquina, en el caso de la gubernamental ${ }^{4}$, lo que resulta es que no hay soberanía sin economía, y viceversa.

En este sentido, ya desde las primeras líneas de El reino y la gloria, el término oikonomía es entendido, de acuerdo a su etimología griega, como el "gobierno de los hombres"5 en tanto administración y organización de la casa. Es decir, la tesis de Agamben es que la problematización que busca dilucidar el término economía en los debates contemporáneos, encuentra su suelo germinal a partir de las consideraciones teológicas sobre la relación entre soberanía y gobierno. Por lo tanto, la intención de la genealogía allí desarrollada no es otra que situar el problema del "gobierno en su locus teológico."6 De este modo, el autor logra asentar el problema de la economía en la perspectiva abierta por los escritos de los teólogos medievales y, fundamentalmente, de los padres de la iglesia sobre la cuestión del gobierno divino del mundo.

Ahora bien, y sin entrar en un tallado más fino del despliegue genealógico agambeniano por razones de espacio, podemos esquematizar esta gran genealogía en tres etapas que solo se comprenden en su interconexión: en primer lugar se exponen los orígenes de la cesura teológica entre ser y obrar; luego, se

4 Agamben utiliza diferentes sintagmas que incluyen la noción de máquina como "máquina soberana", "máquina biopolítica", "máquina antropológica", entre otros, para dar cuenta de los dispositivos con que se forma y captura al mismo tiempo la vida humana. El modelo de la máquina es una reelaboración agambeniana, tal como señala Andrea Cavalletti (Cf. Andrea Cavalletti, El filósofo inoperoso, "Deus Mortalis. Cuadernos de Filosofía Política. Dossier: Giorgio Agamben”, s/d, págs. 51 a 71), que superpone dos modelos cognoscitivos. En primer lugar, el modelo de la "máquina mitológica" desarrollado por el mitólogo italiano Furio Jesi, que muestra un proceso de producción (de mitologías) doble ya que por un lado la máquina produce las mitologías pero por el otro no produce el mito, y su consistencia radica en hacernos suponer, o al menos preguntar, la existencia del mito y perder así de vista las mitologías. En este sentido, la máquina aísla lo que no produce, y lo reserva a su interior más extraño. Y luego, en relación a ello, Agamben toma el modelo de la excepción tomado a partir de las consideraciones de Carl Schmitt sobre la soberanía, y lo superpone al de la máquina para trasladar el enfoque desde la ciencia de los mitos y la antropología al terreno sinuoso en que se cruzan política y ontología, pero también para explicar "el automatismo vital" de la máquina. En otras palabras, ese aislamiento en su interior de una no-producción se explica ahora por el movimiento topológico al que remite la excepción, esto es, la configuración de una zona de indistinción entre inclusión y exclusión donde en sentido estricto no se puede diferenciar el interior y el exterior de la máquina, lo que le confiere su increíble capacidad de captura y poder. Ahora bien, este modelo gnosoleógico no tiene un alcance universal como tampoco una consistencia particular de "caso", ya que el mismo no se mueve de lo universal a lo particular o viceversa, sino que va de lo particular a lo particular por medio de un gesto analógico y paradigmático/ejemplar. En este sentido, en el pensamiento agambeniano, no hay un modelo gnoseológico separado de sus objetos de conocimiento, sino más bien una coincidencia sin fisuras en la exposición paradigmática/ejemplar que (con) el modelo realiza. Y ello le confiere a la máquina un carácter ontológico y no meramente epistemológico, o más bien la inversión ontológica de toda episteme. Cf. Giorgio Agamben, Signatura rerum. Sobre el método, Buenos Aires, Adriana Hidalgo, 2009, págs. 42-43.

${ }_{5}$ Giorgio Agamben, El reino y la gloria. Una genealogía teológica de la economía y del gobierno, Homo sacer II, 2, Buenos Aires, Adriana Hidalgo, 2008, pág. 9.

6 Ídem. 
estudia y analiza la articulación funcional entre ambos en las figuras del reino y del gobierno; y, finalmente, se presenta el dispositivo de "la gloria" en tanto insustancialidad performativa que posibilita y asegura dicha articulación.

Podríamos decir que esta estructura ternaria en que se expone la genealogía del poder de El reino y la gloria. Una genealogía teológica de la economía y del gobierno. Homo sacer II, 2 del año 2007, complementa y resignifica los estudios previos de la saga Homo sacer (que estarían compuestos por Homo sacer I. El poder soberano y la nuda vida de 1995; Estado de excepción. Homo sacer II,1 de 2003; y, finalmente, por Lo que queda de Auschwitz. El archivo y el testigo. Homo Sacer III de 1998). Si en estas publicaciones se estudiaba el poder como capacidad de decisión soberana sobre la vida humana (y por ello desde siempre bio-político), con El reino y la gloria se estudia la forma en que esa capacidad de decisión puede obrar en la forma del gobierno, es decir, como administración económica -lo que se mostraba necesario para entender no sólo la decisión, sino el obrar de todo poder, o mejor aún la conjunción entre decisión y obrar. Pero la novedad con que se encontró dicha complementación es la aparición de un tercer tópico que asegura la relación entre los primeros (entre soberanía y gobierno): es aquí donde emerge la figura de la "gloria", que retrata al poder en tanto majestuosidad ceremonial y litúrgica ${ }^{7}$. En relación a ello, las pregunta centrales que guiaron esta indagación, que visiblemente sufrió modificaciones imprevistas en su desarrollo, son: “¿por qué el poder necesita la gloria? Si este es esencialmente fuerza [soberanía] y capacidad de acción y gobierno, ¿por qué asume la forma rígida, embarazosa y 'gloriosa' de las ceremonias, de las declamaciones y de los protocolos? ¿Cuál es la relación entre economía y Gloria?"8

Por lo tanto, a lo largo de su indagación, Agamben progresivamente centra la cuestión de la división entre el ser y el obrar de Dios, que se sedimenta en la articulación funcional entre Reino y Gobierno, en la figura extrema de la glorificación recíproca que los dos polos de la máquina operan entre sí. Si el paradigma teológico-político (que guió las indagaciones de las primeras publicaciones de Homo sacer) funda la soberanía como poder trascendente en analogía a la postulación del único Dios, el paradigma teológico-económico sustituye dicha idea por la de una oikonomía entendida como un orden inmanente tanto de la vida divina como de la humana?.

\footnotetext{
${ }^{7}$ En uno de sus últimos libros, Agamben complejiza y profundiza esta división y articulación entre decisión y obra situando el punto de indiferencia entre ambas en la noción litúrgica de operación, que se presenta como consustancial a sus análisis de la gloria. Cf. Giorgio Agamben, Opus dei. Archeollogia dell'ufficio, Homo sacer II, 5, Torino, Bollati Boringhieri, 2012.

8 Ídem, pág. 10.

9 En un libro reciente, Rodrigo Karmy explicita de forma concreta y fehaciente esta duplicidad constitutiva de la máquina gubernamental. Cf. Rodrigo Karmy, Politicas de la ex-carnación. Para una genalogía teológica de la biopolítica, Buenos Aires, Unipe, 2014, primera parte.
} 
En este sentido, ya en el primer capítulo de El reino y la gloria, Agamben demarca el campo de la filosofía contemporánea donde realiza su intervención. Éste se circunscribe al debate de mediados de los años sesenta en Alemania, donde participaron en diversa medida autores como Hans Blumenberg, Karl Löwith, Odo Marquard, Carl Schmitt y Erich Peterson. En el centro del debate estaba situado el problema de la secularización, lo cual reenviaba al mismo a la tesis schmittiana de 1922, según la cual todos los conceptos políticos modernos decisivos son en realidad conceptos teológicos secularizados. El italiano recupera allí la tesis de Peterson contra Schmitt, donde se muestra cómo el dogma trinitario en la teología cristiana hace imposible reconducir los problemas políticos de la unidad soberana hacia la misma teología (lo que a fin de cuentas significa que la "teología política" es teológicamente imposible). Ahora bien, como muestra Agamben, esto no implica necesariamente desechar el paradigma teológico para comprender el mundo moderno, sino más bien una reformulación del mismo. La apuesta agambeniana será por lo tanto postular "la tesis según la cual la economía podría ser un paradigma teológico secularizado" 10 , y de este modo abrir un nuevo campo de indagaciones de donde se extrae como conclusión principal que las herencias teológicas de la modernidad no se circunscriben a la soberanía fundada por el mono-teísmo, sino más bien a su articulación con el paradigma de la acción divina, es decir, al ordenamiento que Dios hace sobre el mundo, a su economía.

Es sobre el trasfondo de esta discusión "teológica" y "política" donde el italiano abre y comienza su derrotero genealógico sobre la cuestión de la economía. Con una singular capciosidad, Agamben muestra cómo el terreno de la oikonomía preparado por Aristóteles y el período helenístico fue la caja de herramientas por la cual los primeros padres de la iglesia trataron de conciliar el problema de la trinidad (Dios en cuanto Padre, Hijo y Espíritu Santo). El objetivo era evitar que tal división del poder divino volviera a caer en el politeísmo y/o el paganismo. Como afirma Bacarlett Pérez, "la cuestión era saber cómo, si hay un solo Dios, éste puede desplegarse en tres entidades sin perder su unidad o, peor aún, al desplegarse en la forma del Hijo, al mundanizarse, ¿no pierde sus

${ }^{10}$ Op. Cit. Pág. 16. La tesis schmittiana de la herencia teológica de los modernos conceptos políticos marca específicamente una nueva interpretación sobre la noción de "secularización". Si bien ella no significa una identidad de sustancia entre ambos regímenes conceptuales como tampoco una identidad de significado, el hecho de que los primeros (los modernos) fueran "conceptos teológicos secularizados" significa que mantienen "una relación estratégica particular, que marca los conceptos políticos, remitiéndolos a su origen teológico.” (Op. cit., pág. 18.) De este modo, la secularización, en vez de actuar como una barrera de corte, funciona más bien como una suerte de pasaje que permite a los conceptos modernos remitirse a su origen teológico. Ahora bien, si según Schmitt la filosofía política y la teoría moderna de la soberanía derivan de este pasaje, la inversión petersoniana recuperada por Agamben implica más bien que es el paradigma económico-gubernamental el que seculariza los conceptos teológicos referidos a la acción divina y así los transfiere a la moderna gestión biopolítica de todo aspecto de la vida social.

Araucaria. Revista Iberoamericana de Filosofía, Política y Humanidades, año 17, n 33. Primer semestre de 2015. Pp. 107-122. ISSN 1575-6823 e-ISSN 2340-2199 doi: 10.12795/araucaria.2015.i33.05 
atributos divinos?"11 La primera estrategia puesta en marcha (cuyo principal exponente fue Pablo de Tarso) fue concebir tal división como una economía en función de un encargo: hay una "economía del misterio" que consiste en un "encargo confiado por Dios", respetando el tradicional sentido griego y latino del término economía en tanto "actividad ordenada a un fin" 12 . Pero el problema central de dicha estrategia era que aún se mantenía la división entre Dios y su economía, ya que aquel encargaba algo y otros lo cumplirían, lo cual hacía posible reintroducir otras figuras divinas dado que en nombre de él podrían buscar reivindicar tal condición. Es por esto, y principalmente por medio de los escritos de Hipólito y Tertuliano, que se debió pasar de la inicial formulación de "la economía del misterio" al "misterio de la economía" donde ya no habría una división entre Dios y su economía dirigida hacia el misterio, sino que la propia economía se presentaría como un misterio. Por lo tanto, hay en sentido propio una praxis divina, y no un mero encargo. De este modo se establece lo divino en dos planos diferenciados: Dios será uno en cuanto a su sustancia, pero es múltiple en cuanto a su oikonomía. No se recae así en una politeísmo dado que Dios es uno en cuanto a su ser, pero se logra explicar la heterogeneidad divina inscripta por el dogma de la trinidad en tanto Dios será múltiple en su obrar ${ }^{13}$.

Ahora bien, la consecuencia primordial de haber evitado la proliferación pagana de figuras divinas, por medio de un desdoblamiento constitutivo de Dios en cuanto a su sustancia y a su oikonomía, devino en una cesura irreconciliable -que la modernidad ha cargado sin cesar sobre sus espaldas- "entre Dios y su acción, entre ontología y praxis"14. Por esto mismo, sobre el recorrido de tensiones polares que se abre a partir de "un ser en sí incapaz de acción y una acción sin ser" 15 , versará para Agamben el posterior armado de la teología y los cimientos de la moderna relación Estado-Economía. Si en dicha fractura se despedaza todo fundamento sustancial de la praxis económica, la misma se inscribe desde siempre en una libertad y anarquía constitutivas (an-archos, en el sentido de sin principio ni fundamento) que hacen posible y necesario, por ello mismo, su gobierno. Por lo tanto, hay una correspondencia radical - contraria a las hipótesis bien pensantes del gobierno por consenso- entre anarquía y gubernamentalidad. Pero no sólo hay una praxis sin fundamento, sino que también hay, por así decir, un fundamento sin praxis. Es decir, no sólo se produce una radicalización de las labores económicas-gubernamentales por

11 María Luisa Bacarlett Pérez, Giorgio Agamben, del biopoder a la comunidad que viene en "Araucaria. Revista Iberoamericana de Filosofía, Política y Humanidades", 24, (2010), pág. 44.

12 Giorgio Agamben, El reino y la gloria ..., Op. cit., pág. 56.

13 Afirma Agamben: "la oikonomía hace posible una conciliación en la cual un Dios trascendente, a la vez uno y trino, puede - permaneciendo trascendente- asumir sobre sí la cura del mundo y fundar una praxis inmanente de gobierno cuyo misterio supramundano coincide con la historia de la humanidad"Ídem, pág. 96.

${ }^{14}$ Op. cit., pág. 99.

15 Op. cit., pág. 108. 
las que se administra el mundo sin un sentido prefijado, sino que también hay un resto sustancial que es incapaz de acción. Entonces, tenemos la fórmula central en un mitologema recuperado en el debate Peterson-Schmitt: "el rey reina, pero no gobierna"16. Esto significa que el reino está en Dios, que reina, pero no gobierna. Para no caer en la herejía o en el paganismo, se volvía necesario establecer una articulación posible entre el reino de Dios y su gobierno. Las respuestas ensayadas fueron altamente prolíficas, pero en todas ellas fue perfilándose la noción de delegación (que Agamben llama "la vicariedad de todo poder"17). Pero la característica de esta delegación es que no contiene un encargo determinado que los delegados (ángeles, ministerios, burocracia) deben cumplir de forma lineal, sino que esa ejecución del designio divino oscila entre una determinación trascendental y su organización inmanente. De allí que Agamben encuentre en el providencialismo cristiano la matriz paradigmática de dicho funcionamiento, dado que en éste se expresa, a través de un sinnúmero de mecanismos, la voluntad divina como también la libertad de las creaturas mundanas al igual que en la burocracia moderna confluyen la voluntad del Estado y la del funcionario.

Ahora bien, la conclusión a la que arriban estas reflexiones históricas filosóficas del italiano sobre la gestación de los dos paradigmas teológicos, que a partir de su traslación "secular" a la modernidad tensarán las relaciones políticas en este período, será el haber expuesto la gestación de un residuo inoperoso al interior del propio paradigma económico: "el dios que gobierna tiene, en realidad, necesidad del dios inoperoso y lo presupone" ${ }^{18}$. Es decir, en última instancia el dispositivo teológico que realizó la fractura entre el orden del ser y el del hacer, que se trasladó políticamente en las figuras del reino y del gobierno, pero que a su vez articuló sin cesar ambos polos, genera en su propio funcionamiento una inoperosidad (divina). Por lo tanto, la máquina gubernamental -creación última de la teología económica-genera y captura en un mismo movimiento esta inoperosidad, poniéndola en una esfera separada, impidiendo así pensarla y activarla contra la operosidad extrema de la propia máquina. ${ }^{19}$ A partir de ello, la cuestión central será dilucidar cómo puede la máquina apresar esta inoperosidad y al mismo tiempo sostenerse en

${ }^{16}$ Cf. Op. cit., págs. 125 y ss.

${ }^{17}$ Cf. Op. cit., págs. 242 y ss.

18 Op. cit., pág. 141.

19 Por lo tanto, en última instancia, en la máquina gubernamental se solapan sin cesar operosidad e inoperosidad. Ambas figuras en Agamben tendrán un peso específico: mientras que la primera define a la biopolítica y gubernamentalidad moderna, la segunda será propiamente la política por venir. Como afirma Andrea Cavalletti, "El exterior de la máquina es acción, praxis, obra vuelta hacia la producción, proceso de incesante partición; el interior es ausencia de obra. Y dado que la máquina captura la inoperosidad separándola, puede operar una serie ilimitada de particiones en sus diferentes declinaciones históricas. El poder, lugar de todas las separaciones y todas las capturas, no es más que la separación de la inoperosidad, es la forma siempre móvil y mutable de esta primer captura" ("El filósofo inoperoso" en $O p$. cit., pág. 56). 
ella. El dispositivo que surge y se revela como específico de este proceder es precisamente la noción de gloria, y es aquí donde reside la novedad del gesto agambeniano en tanto permitirá distinguir ontológicamente el poder de su subversión.

El autor encuentra el espacio de esta articulación, entre un poder que se trasciende en su inoperosidad y un poder que se ejercita y opera inmanentemente, en las aparentemente superfluas adyacencias de los mecanismos del poder como son los protocolos, las aclamaciones, los cantos, las alabanzas, las liturgias y las ceremonias. Es en estos tópicos, que la teología circunscribe precisamente en los ángeles en tanto enviados de Dios, donde la gloria encuentra su asidero y permite pensar al poder en su conjunción de sustancia trascendente y ejercicio inmanente. De este modo, tal como señala Bacarlett Pérez, la gloria permite principalmente tres cosas: en primer lugar, disfrazar y ocultar la inoperosidad divina, es decir, su incapacidad de actuar directamente sobre el mundo; en segundo término, la gloria tiene como función incrementar el poder al volverlo fasto e intocable; y, por último, sirve de lazo entre el Reino y el Gobierno ya que les permite remitirse el uno al otro, el primero para poder operar y el segundo para legitimarse en sus operaciones. ${ }^{20}$ Esta última será la función más importante dado que en ella se comprende cómo la gloria es la resultante de la mutua reciprocidad entre ser y praxis, entre Reino y Gobierno, entre trascendencia e inmanencia. Por ello no hay una gloria propiamente dicha, sino más bien una glorificación recíproca donde en un sistema de espejos enfrentados uno se ve en el otro para encontrarse a sí mismo, y así por inversión reflectante hasta el infinito. Por ello, la gloria es el balanceo que estabiliza, o mejor que tensa, la relación entre los dos polos divididos. Los ángeles glorifican a Dios como éste los glorifica a ellos, y en ese movimiento pendular queda apresada la inoperosidad divina y de este modo resguardada en una esfera separada, pero también asegurada la operosidad interminable de los ángeles. Pero el centro de la articulación está vacío, por lo que a fin de cuentas "la gloria no es más que el esplendor que emana de aquel vacío" 21 . Por lo tanto, el centro vacío y desnudo del poder queda velado por el manto de gloria que lo recubre, que termina en sí mismo por justificar la operosidad económica incomparable a la que ha dado lugar, no ya por las obras que realiza, sino en cómo éstas glorifican lo que desde siempre es glorioso: el ser de Dios. De este modo, con su característica de luz cegadora, la gloria se manifiesta como el lugar en que se exhibe/expone el vacío constitutivo de la máquina para, en un mismo movimiento, retirarlo a una esfera separada que sólo admite con él una relación cultual, el decir, litúrgica,

\footnotetext{
${ }^{20}$ Cf. Bacarlett Pérez, María Luisa. “Giorgio Agamben, del biopoder...”, Op. cit., pág. 46.

${ }^{21}$ Giorgio Agamben, El reino y la gloria..., op. cit., pág. 369. Y en el "esplendor" que emana del vacío podemos ver lo que ya a mediados de la década del treinta, Benjamin denunciaba como la “estetización de la política” Cf. Walter Benjamin, La obra de arte en la época de su reproductibilidad técnica [Urtext], traducción de Andrés E. Weikert en www.upv.es/laboluz/master/seminario/morey/ URTEXT.doc
} 
impidiendo así una inoperosidad descentrada del gobierno. El sentido de dicha inoperosidad abre la cuestión de lo ingobernable.

\section{Inoperosidad y potencia}

El objetivo del apartado precedente era dar cuenta de la producción y aislamiento al interior de la máquina gubernamental de la inoperosidad, es decir, el modo histórico en que para Agamben asume esa configuración del poder. Ahora bien, siguiendo el sistema de analogías al que el pensamiento del autor italiano nos dirige una y otra vez, podemos afirmar que este desarrollo se encuentra íntimamente ligado a dos problemáticas aristotélicas que recorren internamente casi toda la obra del italiano: la cuestión de la potencia y la cuestión de la obra. Dos ensayos se vuelven aquí fundamentales: La potencia del pensamiento y La obra del hombre ${ }^{22}$.

En este sentido, sostendremos que la estrategia agambeniana consistirá en preparar el terreno ontológico por medio del par aristotélico potenciaacto, extraído de la Física y la Metafísica del estagirita para dar cuenta de la política que allí se inscribe: la de la inoperosidad, extraída más bien de la Ética aristotélica. Como señala Agamben, la potencia que Aristóteles intentaba calibrar no es aquella potencia genérica como la que poseen los niños de poder ser cualquier cosa (guitarrista, arquitecto); sino más bien la potencia específica que surge del tener una facultad (tener la facultad de tocar la guitarra, de construir). El niño deberá sufrir una alteración para ser potente, en cambio quien posee una técnica será potente por ese mismo tener. Por lo tanto, no está en cuestión una potencia de ser absoluta sino más bien el tener de una potencia específica, una facultad de ser o hacer. Pero la centralidad de la lectura agambeniana consistirá en mostrar la ambivalencia constitutiva de esta noción de potencia dado que, recordando por medio de una filología cuidada, uno de los pasajes característicos del libro Theta de la Metafísica, Agamben señala a partir de Aristóteles "la ambivalencia específica de toda potencia humana, que, en su estructura originaria, se mantiene en relación con la propia privación; [porque la potencia] es siempre $-\mathrm{y}$ respecto de la misma cosa- potencia de ser y de no ser, de hacer y de no hacer" 23 .

De este modo, y reconociendo que la potencia admite en su seno el ser como el no-ser, lo que se tiene al tener una facultad es una privación (stéresis). El tener una privación se denomina en el griego de Aristóteles héxis que

\footnotetext{
22 Ambos publicados en el recopilado de ensayos y conferencias en Giorgio Agamben, La potencia del pensamiento, Buenos Aires, Adriana Hidalgo, 2007. Mientras el primero es una conferencia pronunciada en Lisboa en 1987, el segundo es un texto aparecido en la revista Forme di vita del año 2004.
}

23 Íbid., pág. 361.

Araucaria. Revista Iberoamericana de Filosofía, Politica y Humanidades, año 17, $\mathrm{n}^{\circ} 33$. Primer semestre de 2015. Pp. 107-122. ISSN 1575-6823 e-ISSN 2340-2199 doi: 10.12795/araucaria.2015.i33.05 
significa ni más ni menos que "tener una potencia", y ello implica que lo mismo puede ser como no-ser, puede pasar al acto como no pasar. Por lo tanto, en la potencia lo afirmativo y lo negativo no se mantienen en una relación excluyente, sino que más bien se co-pertenecen: tener una privación no es una simple negación, ni tampoco una afirmación. Es una capacidad que puede no ejercerse (el guitarrista cuando no toca su guitarra, el arquitecto cuando no construye). Y este doble carácter define la contingencia radical de todo poder y obrar, por lo que no es menos que atinada el elogio de Andrea Cavalletti al afirmar que Agamben "inaugura en el corazón mismo de la tradición metafísica una nueva ontología de lo contingente"24.

Ahora bien, si "el hombre es el animal que puede la propia impotencia"25, ¿qué sucede con la potencia y su carácter anfibio en el momento en que se pasa al acto? Y, en consecuencia, ¿cuál será el acto de la potencia de no pasar al acto? Para responder estos interrogantes, Agamben traduce uno de los pasajes más enigmáticos de la Metafísica del siguiente modo: "Es potente aquello para lo cual, si sucede el acto del que es dicho que tiene la potencia, nada tendrá de impotente"26. Lejos de encontrar una tautología en ese "nada tendrá de impotente" - como han hecho los intérpretes modernos-, el italiano lee allí la radicalidad del gesto aristotélico: "nada tendrá de impotente" sería, correctamente traducido según Agamben, "nada tendrá de potente no (ser o hacer)", por lo que se inscribe una doble negación que lejos de resolverse en una nueva afirmación, se sostendrá en una indistinción entre lo afirmativo y lo negativo. Cuando se da el pleno pasaje al acto, éste no anula la potencia de no, sino que la convierte en una potencia de no-no pasar al acto. La potencia sobrevive en la misma privación del acto, pero dicha potencia no es sino la propia privación, esto es, la potencia de no. Todo esto se clarifica cuando se comprende que, como afirma Cavalletti, "la relación potencia-acto no es más que la misma relación interna de la potencia" ${ }^{27}$. En otras palabras, el acto y la potencia refieren al carácter anfibio propio de la potencia, lo cual desvía el foco de atención ya que la pregunta ahora no versa sobre cómo pasar al acto, sino más bien sobre cómo tener y conservar una potencia, incluso en el pasaje al acto (que según Agamben ese "modo de tener la potencia" es el significado original de los términos aristotélicos héxis y su traducción latina, habitus).

De este modo, en todo acto queda resguardado el carácter bipolar de la potencia, ya que una realización absoluta del acto no es sino una anulación absoluta de la potencia, pero como ella puede contener su contrario, su potencia de no, no es sino una darse de ella misma: potencia de no-no pasar al acto, eso es el acto. Por lo tanto, es este carácter potencial lo que queda abandonado en todo acto, el resto

\footnotetext{
${ }^{24}$ Cavalletti, Andrea. El filósofo inoperoso..., cit., pág. 64.

${ }^{25}$ Giorgio Agamben, La potencia del pensamiento..., op. cit., pág. 362.

26 Íbid., pág. 364. Las cursivas son nuestras.

27 Cavalletti, Andrea. El filósofo inoperoso..., op. cit., pág. 64.
} 
último del engranaje potencia-acto. Es ése el nutriente de todo poder, el combustible de la máquina. Es precisamente este reservorio el que habíamos mostrado con el dispositivo de la gloria que se llama inoperosidad. Es aquí donde entra en juego el segundo ensayo mencionado anteriormente, La obra del hombre.

Como ha señalado el propio Agamben en una entrevista reciente, el término inoperositá, en italiano, parte de la tradición francesa del désoeuvrement donde desfilan diversos pensadores, para polemizar con algunas versiones que han hecho de ella una simple ausencia de obra. Para el italiano, la inoperosidad se trata "de una praxis, de una operación que consiste en volver inoperosas todas las obras humanas." ${ }^{28}$ Tal como afirma Jean-Luc Nancy respecto de la comunidad:

El inacabamiento es su 'principio' -pero en el sentido en que el inacabamiento debería ser tomado como un término activo, designando no la insuficiencia o la falta, sino la actividad del reparto, la dinámica, si puede decirse, del tránsito ininterrumpido por las rupturas singulares. Vale decir, otra vez, una actividad inoperante. No se trata de hacer, ni de producir, ni de instalar una comunidad; tampoco se trata de venerar o de temer un poder sagrado en ella. Se trata de inacabar su reparto ${ }^{29}$.

En este sentido, de lo mismo se trata para Agamben: una comunidad que vive de sus obras inoperantes, o mejor, de la inoperancia que las sobrevive y las abre al reparto de lo común, pero que no las niega, sino que las excede continuamente. Ahora bien, ¿qué puede significar una obra que deshace las obras, una operación que, si se nos permite el neologismo verbal, inopera? ¿Y cómo ello encuentra su asidero en la relación potencia-acto, o más bien, en la potencia misma? Y sobre el telón de fondo de estos interrogantes, ¿cómo puede lo inoperoso ser lo ingobernable y sin embargo darse allí como la política democrática que aquí estamos intentando pensar?

En el segundo ensayo que aquí estamos siguiendo, Agamben retoma un pequeño pasaje de la Ética Nicomaquea, donde Aristóteles evoca por un momento la posible falta de obra que definiría al hombre, a diferencia de las figuras sociales que pueda adquirir, para quienes habrían obras propiamente dichas que los definirían (el músico, el carpintero, el zapatero). La importancia de esto es que para el griego descubrir y vivir de acuerdo a esa obra constituiría el bien supremo, y con ello no sólo su esencia y naturaleza, sino también su política y felicidad. De este modo -prosigue Agamben-, Aristóteles intenta buscar la especificidad de la obra humana en el ámbito de la vida. Pero esta no puede ser la simple vida natural (la zoé) porque en ella misma no se diferencian las plantas y los animales del hombre, por lo

28 Giorgio Agamben, Oeuvrer/Désoeuvrer: en quête d'un nouveau paradigme. Entretien avec Giorgio Agamben, préparé et présenté par Aliocha Wald Lasowski en "Agenda de la pensé contemporaine”, 16 (printemps 2010), Paris, Hermann, págs. 35-46. Traducción propia.

29 Jean-Luc Nancy, La comunidad inoperante, Santiago, Arcis, 2000, pág. 46. 
que la especificidad humana es la vida que vive según el logos (el bios). Pero al mismo tiempo, esa vida según el logos no puede ser en potencia, sino solamente en acto: así, el hombre tiene como obra específica el uso de la razón, el $\log o s$, y ello es el vivir bien. ${ }^{30}$

Esto dejará como legado a Occidente dos aporías políticas: en primer lugar, la política solo puede serlo del acto y de la obra, no de la potencia ni de la inoperosidad; y, en segundo lugar, esa política de la obra se funda sobre una exclusión de la nuda vida, es decir, aquella que no ejercita el logos. La política es así atada a una obra que transciende a todas las obras singulares de los hombres y al mismo tiempo se forja sobre una división de la vida entre vida política y vida impolítica -que en las intensificaciones históricas de estas aporías, han dado lugar a una división entre vida que merece vivir y vida desechable. Esta ha sido, desde la interpretación agambeniana, la lectura imperante sobre la obra de Aristóteles y sobre la que se ha forjado el paradigma gubernamental (la primera aporía) y el biopolítico (la segunda aporía).

Contra esa lectura, Agamben recupera el "hilo secreto" que como un cauce subterráneo acompañó de forma contrapuesta a la tradición occidental en una reivindicación de la potencia sobre el acto, de la inoperosidad sobre la obra, contenida principalmente en los escritos de Averroes y Dante ${ }^{31}$. No es nuestra intención reconstruir la totalidad del argumento, sino señalar dos conclusiones a las que arriba la lectura agambeniana: en primer lugar, y a partir de las anteriores reflexiones en torno a la potencia, la búsqueda de una inoperosidad esencial del hombre no implica una pasividad radical sino ante todo un confrontarse "cuerpo a cuerpo"32 con los dispositivos que han capturado la potencia y la inoperosidad en el acto y la obra, y allí los han abandonado. Ello implica una suerte de reconquista que se juega dentro de los dispositivos del poder. $\mathrm{Y}$, en segundo lugar, la inoperosidad que se expone en cada acto su potencia constitutiva y lo abre a nuevos devenires no puede ser sino común dado que no puede quedar atada a ninguna obra específica, pero tampoco separada de ellos mismos. Por lo tanto, esa potencia de inoperosidad es simultáneamente disruptiva e inventiva, ya que rompe el anquilosamiento aislado en que la sitúa la máquina gloriosa gubernamental al mismo tiempo que inaugura un nuevo uso del exceso potencial que contiene toda obra, todo acto, que por el mismo exceso constitutivo de la potencia no puede ser sino común, múltiple.

${ }^{30}$ Lo cual mostraría el nexo constitutivo entre vida y política, es decir, biopolítico en el pensamiento griego, que Agamben había señalado ya polémicamente en la "Introducción" de Homo sacer I. El poder soberano y la nuda vida, Valencia, España, Pre-textos, 2003.

31 Para una atenta reconstrucción de esta lectura "esencial" en el pensamiento de Agamben, cf. Rodrigo Karmy Bolton, "Potentia Pasiva. Giorgio Agamben lector de Averroes" [en Rodrigo Karmy Bolton ed. Politicas de la interrupción. Ensayos sobre Giorgio Agamben, Santiago de Chile, Escaparate, 2011], pág. 14.

32 Giorgio Agamben, El autor como gesto [en Profanaciones, Buenos Aires, Adriana Hidalgo, 2009], pág. 93.

Araucaria. Revista Iberoamericana de Filosofía, Política y Humanidades, año 17, no 33. Primer semestre de 2015. Pp. 107-122. ISSN 1575-6823 e-ISSN 2340-2199 doi: 10.12795/araucaria.2015.i33.05 


\section{Ingobernable democrático}

Si probamos pensar la democracia en esa inoperosidad común y múltiple, podemos afirmar que todas las obras y los actos de la democracia (leyes, decretos, políticas públicas, ordenamientos, etc.) tiene algo así como una doble vertiente: por un lado, todo un tejido de actos y obras que no hacen sino gobernar la vida de los hombres, pero también, y en la misma medida, un reparto y exposición de un exceso que no se deja reducir a los actos y a las obras mismas, para decirlo en otros términos, un exceso ingobernable. La pregunta por la democracia, en última instancia, es por la forma en que toma a su cargo ese exceso ingobernable que la caracteriza.

Así, tenemos una democracia que busca agotar ese exceso y controlarlo en una red gubernamental, lo que redunda en una gestión biopolítica del mismo, o más bien en una pura administración tecnocrática que empieza a ocupar cada espacio de la vida social hasta confundirse con ella misma. El extremo de este proceso es, tal como la famosa y más criticada tesis de Agamben enuncia, el campo de concentración donde la vida queda reducida a su pura biología y así dispuesta a cualquier decisión soberana que fije el punto en que ella pueda convertirse o no en muerte ${ }^{33}$. Sin embargo, otra democracia es pensable desde estas categorías. Una democracia que asume lo ingobernable y se encarga de repartirlo, de exponerlo.

Ahora bien, ¿cuál será la definición más justa de este ingobernable que ya no se piensa exterior al poder sino como su nutriente más íntimo, su exceso incontrolable, su reservorio implacable? Quisiéramos postular que solamente es asible en inmanencia, esto es, sin definiciones ni mediciones previas. Pero podríamos dar un paso más: esa inmanencia es el ejemplo. Si la democracia ya no puede ser pensable desde la pura legalidad estatal ni tampoco desde la absoluta administración económica, ¿por qué no anclar el término en una serie de formas-de-vidas ejemplares? Creemos que la ventaja de sistematizar la comunidad política en la figura del ejemplo tiene una consideración estrecha a la figura de la inmanencia: no hay meta-ejemplo. El ejemplo del ejemplo es siempre otro ejemplo, y tal como ha mostrado Agamben, éste no refiere a un conjunto previamente constituido sino que por el contrario suspende en su misma exposición al conjunto al que se refiere, para en esa suspensión demarcar su pertenencia singular al conjunto - de otro modo no se entendería por qué se exponen los ejemplos. Esto se debe a que el conjunto no está presupuesto, sino que es inmanente a la misma exposición ejemplar. Es decir, no comprueba nada previo ni tampoco está absolutamente separado, es en cambio la forma misma en que se constituye un conjunto ${ }^{34}$.

\footnotetext{
${ }^{33}$ Cf. Giorgio Agamben, Homo sacer..., op. cit., tercera parte.

${ }^{34}$ Giorgio Agamben, Signatura rerum ..., op. cit., pág. 42.
} 
Por lo tanto, si ya no queremos gobernarnos por medio de un aparato institucional codificado que inscribe cesuras interminables en la vida como tampoco por una serie de técnicas gubernamentales que diagraman la operosidad incesante de la vida, ¿por qué no asumir formas-de-vida ejemplares para in-gobernarnos? ¿Por qué no inscribir la democracia en la asunción vital del ejemplo? Y escribimos in-gobernarnos porque los ejemplos son tales, por todo lo que ya hemos dicho, en tanto y en cuanto exponen en sí mismos la inoperosidad y potencia que rompe los nichos de anquilosamiento y captura de la máquina gubernamental, es decir, en cuanto han sido y son ingobernables. La comunidad que se constituye en base al ingobernable ejemplar, siguiéndolo sin imitarlo como reza la fórmula lacaniana, deviene democrática por cuanto se ordena inmanentemente en base a las vidas ejemplares, aquellas que han roto "cuerpo a cuerpo" los dispositivos jurídicos y económicos que capturan y separan una vida de sus formas, la inoperosidad de sus obras. El ejemplo es siempre una copia y exposición de sí que excede lo original, que lo amplía, desautoriza, rehace, deshace, juega con él, al igual que el montaje en el cine. Asumiendo que el ejemplo expande de por sí aquello que ejemplifica, lo que se inscribe en ese gesto es una irreductibilidad que impide su captura. El riesgo de esta democratización es caer en la glorificación litúrgica del ejemplo, cuando lo que caracterizó al mismo fue precisamente la rotura con toda forma preconcebida de glorificación. En contra de esa pubertad litúrgica y aclamatoria consideramos necesario pensar y activar hoy el ingobernable democrático. 


\section{Referencias bibliográficas:}

Agamben, G. El autor como gesto [en Profanaciones, Buenos Aires, Adriana Hidalgo, 2009]

-, El reino y la gloria. Una genealogía teológica de la economía $y$ del gobierno, Homo sacer II, 2, Buenos Aires, Adriana Hidalgo, 2008. , Homo sacer I. El poder soberano y la nuda vida, Valencia, España, Pre-textos, 2003. 2007. , La potencia del pensamiento, Buenos Aires, Adriana Hidalgo, Nota preliminar sobre el concepto de la democracia, [en AAVV. Democracia, ¿en qué Estado?, Buenos Aires, Prometeo, 2011] , Oeuvrer/Désoeuvrer: en quête d'un nouveau paradigme. Entretien avec Giorgio Agamben, préparé et présenté par Aliocha Wald Lasowski en "Agenda de la pensé contemporaine", 16 (printemps 2010), Paris, Hermann.

, Opus dei. Archeollogia dell'ufficio, Homo sacer II, 5, Torino, Bollati Boringhieri, 2012.

Hidalgo, 2009.

Bacarlett Pérez, M. L. Giorgio Agamben, del biopoder a la comunidad que viene en "Araucaria. Revista Iberoamericana de Filosofía, Política y Humanidades", 24, (2010).

Benjamin, W. La obra de arte en la época de su reproductibilidad técnica [Urtext], traducción de Andrés E. Weikert en www.upv.es/laboluz/master/ seminario/morey/URTEXT.doc

Cavalletti, A. El filósofo inoperoso, "Deus Mortalis. Cuadernos de Filosofía Política. Dossier: Giorgio Agamben”, s/d, págs. 51 a 71.

Karmy Bolton, R. Introducción, [en Rodrigo Karmy Bolton, ed.: Políticas de la interrupción. Ensayos sobre Giorgio Agamben, Santiago de Chile, Escaparate, 2011]

teológica de la biopolítica, Buenos Aires, Unipe, 2014. "Potentia Pasiva. Giorgio Agamben lector de Averroes" [en Rodrigo Karmy Bolton ed. Políticas de la interrupción. Ensayos sobre Giorgio Agamben, Santiago de Chile, Escaparate, 2011]. - Nancy, J.-L. La comunidad inoperante, Santiago, Arcis, 2000. 